\title{
Ajaran untuk Istri dalam Serat Patimah
}

\author{
Mirya Anggraeni \\ Fakultas Ilmu Budaya Unversitas Diponegoro \\ Email: mememirya@gmail.com
}

\begin{abstract}
The spiritual heritage of the nation of Indonesia is preserved on a variety of literary works, both native Indonesia values as well as values that come from outside, including the values of Islam. The arrival of Islam enriches the literary treasure in Java. At the moment it appears that works bersumberkan Islam. Among literary works such as the Javanese Islam Serat Patimah containing the advice of Prophet Muhammad to his daughter. In the text that a wife must respect her husband, loving husband, always serve the husband, and according to her husband. In addition, a wife should be respectful of the guest to maintain the good name of her husband. All advice is based on the teachings of Islam.
\end{abstract}

Keywords: spiritual heritage, Islam, Prophet Muhammad, his wife, Serat Patimah

\section{Intisari}

Warisan rohani bangsa Indonesia tersimpan pada berbagai karya sastranya, baik nilainilai asli Indonesia maupun nilai-nilai yang datang dari luar, termasuk nilai-nilai ajaran Islam. Kedatangan Islam memperkaya khazanah sastra di Jawa. Pada saat itu muncul karya-karya yang bersumberkan ajaran Islam.Di antara karya-karya sastra Jawa Islam tersebut misalnya Serat Patimah yang berisi nasihat Nabi Muhammad kepada putrinya. Dalam teks tersebut seorang istri harus menghormati suami, menyayangi suami, selalu melayani suami, dan menurut kepada suaminya. Di samping itu, seorang istri harus menghormati tamu untuk menjaga nama baik suaminya. Semua nasihat itu didasarkan pada ajaran Islam.

Kata kunci: warisan rohani, ajaran Islam, istri, Nabi Muhammad, Serat Patimah.

\section{Pendahuluan}

Indonesia kaya akan karya sastra. Karya-karya sastra tersebut antara lain tersimpan dalam naskah-naskah yang tersebar di Nusantara. Dalam naskah-naskah tersebut terkandung sesuatu yang penting dan berharga, yaitu warisan rohani bangsa Indonesia. Dengan mempelajari sastra itu, dapat diketahui pikiran dan cita-cita para nenek moyang bangsa Indonesia (Robson, 1978: 5). Kandungan yang tersimpan dalam karya-karya sastra masa lampau tersebut pada hakikatnya merupakan produk suatu budaya (Baried dkk, 1994: 2). Demikan juga karya-karya sastra Jawa menyimpan nilai-nilai budaya masyarakatnya. 
Sastra Jawa dimulai pada abad ke-9 (Zoetmulder, 1994: 5). Sejak itu ribuan karya sastra ditulis dengan menggunakan bahasa Jawa. Poerbatjaraka (1952) menggolongkan sastra Jawa menjadi tujuh, yaitu kitab-kitab Jawa Kuno golongan tua, kitab-kitab Jawa Kuno yang bertembang, kitab-kitab Jawa Kuno yang tergolong baru, kitab berbahasa Jawa Tengahan, kitab berbahasa Jawa Tengahan yang bertembang, karya-karya zaman Islam, dan karya sastra zaman Surakarta awal.

Kedatangan Islam memperkaya khazanah sastra di Jawa. Pada saat itu muncul karya-karya yang bersumberkan ajaran Islam. Akan tetapi teks-teks tersebut tidak semata-mata berisi ajaran Islam. Dalam teks tersebut terkandung beragam hal seperti sejarah, pendidikan, geografi, arsitektur, pengetahuan alam, falsafah, agama, tasawuf, mistik, ramalan, sulap, ilmu magi, perlambang, adat istiadat, tata cara, etika, pengetahuan sifat manusia, pengetahuan dunia fauna, pengetahuan dunia flora, obat tradisional, makanan tradisional, seni, bahkan sampai hal sanggama yang dianggap porno (Marsono, 2008: 4).

Di antara karya-karya sastra Jawa Islam tersebut misalnya Serat Patimah. Serat tersebut terdiri atas 23 bait. Pupuh ini merupakan nasihat Nabi Muhammad kepada putrinya yang bernama Fatimah untuk berbakti kepada suami, sebagaimana yang tertulis dalam bait pertama.

Nabi juga menasihati Fatimah untuk setia kepada suami dan taat beribadah. Nabi mengajarkan kepada Fatimah untuk rajin membaca Al-Quran, baik siang maupun malam. Selain itu, beliau juga mengajari Fatimah bertaubat karena manusia merupakan mahluk yang tidak luput dari dosa. Taubat merupakan sarana untuk memohon ampun atas segala kesalahan, baik yang disengaja maupun tidak disengaja kepada Allah. Nasihat itu tersirat dalam bait kedua.

\section{Kewajiban Seorang Istri menurut Serat Patimah}

Nasihat Nabi kepada Fatimah tentang bakti seorang istri kepada suami tersirat dalam bait-bait yang tersusun indah dalam pupuh ini. Nasihat atau ajaran Nabi mengenai bakti istri kepada suami dipaparkan di bawah ini.

1. Seorang istri harus menghormati suaminya.

Istri yang mulia ialah istri yang mampu menghormati suaminya. Dalam ajaran Jawa, seorang istri bertugas mendampingi suami. Suami merupakan kepala rumah tangga yang memiliki kedudukan lebih tinggi daripada istri. Artinya, 
suami bertanggung jawab penuh terhadap istrinya. Untuk itu, seorang istri harus menurut kepada suaminya. Seorang istri tidak boleh menyela perkataan suaminya. Ajaran itu tertuang pada bait ke-3 dan 22

den bekti marang ing laki / den rumangsa yen ganjaran / wong lanang ingkang adarbe / lamun sira leligiyan / kalawan lakenira / aja sira jajar luguh / pan iku datan prayoga // (Serat Patimah, bait 3) sakathahe ing pawestri / aja na sak marang priya / mugi tiniruwa mangke / paniku wadon utama / karam manjing naraka / kang murat langkung jumurung / sasat ratu wanudya // (Serat Patimah, bait 22)
Berbaktilah pada suami

Jika merasa akan mendapat ganjaran

Laki-laki yang dimiliki

Jika kamu berkeliling

Bersama suami

Jangan kamu menyamai kedudukannya

Hal itu tidak baik

Kebanyakan seorang istri

Jangan ada yang menyela suami

Semoga nanti dapat ditiru

Itu wanita utama

Haram baginya mendekati neraka

Yang kosong baiknya memberi

Layaknya ratu para wanita

Sikap hormat seorang istri kepada suami juga ditunjukkan dengan perasaan takut kepada suaminya. Takut dalam hal ini adalah sikap tidak menantang suami. Ketika suami dan istri bertengkar, istri harus bersabar dan menekan amarahnya. Selain itu, istri juga selalu memaafkan kekhilafan suaminya. Ajaran itu tersirat dalam bait ke-12 berikut.

yen sira aguling /

iya lawan lakenira /

nedhaa pangapurane /

tan beda yen lunga teka /

sucekna raganira /

sarta lawan toya wulu /

ilang dosa kari rasa //

(Serat Patimah, bait 12)
Jika kamu bertengkar

Melawan suamimu

Mintalah maaf padanya

Tidak berbeda jika datang dan pergi

Sucikan ragamu

Serta dengan meneguk air

Hilang dosa tinggallah rasa

Ketika istri merasa kurang berkenan dengan keputusan suami, istri hendaknya menahan diri. Sampaikan dengan kata-kata yang halus, sopan, dan tanpa amarah. Jika seorang istri menyampaikannya dengan amarah dan kata-kata yang keras, itu adalah aib bagi wanita terhadap suaminya. Seperti yang tersurat dalam bait ke-6 berikut.

manawa tan suka nini / aja sira paripaksa / pan sirik jenenging wadon /
Jika tidak suka

Jangan kamu memaksa

Jangan marah 
iku wadining wadon /

marang ing kakung ira / estokena wulang ingsung / den manis tembung ira // (Serat Patimah, bait 6)
Itu aibnya wanita

Kepada suaminya

izinkanlah aku menasihati

Bertuturlah dengan manis

Seperti halnya suami, istri juga manusia biasa yang memiliki hawa nafsu. Untuk itu, istri dianjurkan untuk berpuasa agar terhindar dari godaan hawa nafsu. Apalagi, jika suami sering bekerja ke luar kota, hendaknya istri rajin untuk berpuasa. Ajaran itu tersirat dalam bait berikut.

den ajrih sira ing laki /

aja pegat apuasa /

lamun tinilar lakine /

ganana akakesahan /

adoh parane ika /

na nedya ing Hyang Agung /

mugi salamet neng paran //

(Serat Patimah, bait 14)
Maka takutlah kamu terhadap suami jangan meninggalkan puasa kalau ditinggal suamimu untuk bepergian jauh sekali perginya itu memohonlah kepada Tuhan semoga selamat sampai tujuan

Melalui berpuasa, doa istri untuk keselamatan suaminya lebih mustajab. Selain itu, ketika istri berpuasa dapat menghindarkan dirinya dari perbuatan dosa. Sehingga, berpuasanya seorang istri merupakan wujud bakti seorang istri kepada suaminya.

Sikap menghormati suami juga diwujudkan dengan sikap tidak tinggi hati kepada suami. Pada pupuh ini juga disebutkan agar Fatimah tidak boleh tinggi hati karena dia adalah putri Nabi.

aja ngegungaken nini /
lamun siraputraning wang /
datan kena kukumane /
wus wajib kabektenana /
pawestri marang priya /
pan yaiku ukumipun /
pawestri tan bekti priya //

(Serat Patimah, bait 21)

\author{
Jangan sombong \\ Meskipun kamu putriku \\ Nanti akan mendapat hukuman \\ Sudah kewajibanmu berbakti \\ Istri terhadap suami \\ Sebab itu adalah hukumnya \\ Istri berbakti pada suami
}

Dalam kehidupan berumah tangga suami memiliki posisi lebih tinggi daripada istri. Oleh karena itu, meskipun istri berasal dari keluarga terpandang atau kaya, dia tidak boleh menyombongkan diri kepada suaminya. Dia harus menghargai dan menghormati suaminya karena kewajiban istri adalah berbakti kepada suami. Jika istri bersikap tinggi hati kepada suaminya, istri akan mendapatkan hukuman dan adab dari Allah. 
2. Seorang istri harus menyayangi suaminya.

Dalam kehidupan berumah tangga hendaknya suami dan istri selalu menunjukkan sikap saling menyayangi agar keluarganya hidup tentram dan bahagia. Kehangatan dalam keluarga sangat dibutuhkan agar tercipta suasana rumah yang damai. Kedamaian yang tercipta dalam keluarga akan memberikan pengaruh yang baik terhadap psikologi suami, istri, dan anak-anaknya. Dalam hal ini peran seorang istri begitu besar dalam membangkitkan rasa asih dalam keluarga, terutama kepada suaminya. Rasa sayang seorang istri kepada suami ditunjukkan melalui kehalusan budi dan tutur kata. Seperti yang tersirat dalam bait ke-15 dan 18 berikut.

\section{Lamun lakenira prapti / egal nulia maraa / nulya sapanen den age / dipun sumeh ulat ira / kang ana sajekena / yen tan darbe banyu banyu / dadiya pratandha tresna // (Serat Patimah, bait 15)}

panutane ing pawestri / leh ira bekti ing priya / aja kaya jaman mangke I pawestri nganggep ing priya / lamun kakung prapta / palerok rebut dhucung / nora nedya ngaruhana // (Serat Patimah, bait 18)
Jika suamimu telah pulang Lalu segeralah mendatanginya Maka kemuliaan akan datang padamu Pandangan dengan murah senyum Yang kamu sajikan Jangan menunjukkan wajah sedih Tunjukkanlah pertanda cinta

Menjadi panutan untuk seorang istri Berbaktilah pada suami Jangan seperti zaman yang akan datang Istri tidak menghormati suami Jika suami datang Pancaran mata seperti ingin berkelahi Tidak mau menyapa

Pada kutipan itu tersirat ajaran untuk selalu memasang raut muka yang manis, ceria, dan senyum menyejukkan ketika menyambut suami yang datang dari bekerja. Istri hendaknya menyapa suaminya dengan sapaan yang halus dan tutur kata yang manis. Sikap semacam ini mampu menyejukkan hati suami dan menghilangkan penatnya setelah seharian bekerja mencari nafkah untuk keluarga.

3. Seorang istri harus melayani suaminya.

Salah satu kewajiban seorang istri ialah melayani suami lahir dan batin. Secara lahiriah, seorang istri hendaknya melayani suaminya dengan memasakkan dan menyajikan makanan untuk suaminya. Ajaran seperti itu tersirat dalam bait ke13 berikut. 
den nastiti ngati-ati / yen sira adang lan kelan / aja ngusap ing remane / aja sira anggeganda / den sertu lawan toya/ lan aja ngliga perbayun / iku ageng dosa nira // (Serat Patimah, bait 13)
Maka cermat dan berhati hatilah Jika kamu memasak nasi dan sayur Jangan sambil mengusap rambut Jangan kamu suka mengendus Maka seperti api melawan air Dan jangan bertelanjang dada Itu membuatmu memiliki dosa besar

Pada kutipan tersebut terdapat ajaran untuk cermat dan berhati-hati ketika memasak dan menyajikan makanan untuk suami. Istri tidak boleh mengendus dan mengusap makanan yang akan disajikan kepada suaminya. Selain itu, ketika menyajikan makanan kepada suami, istri hendaknya menggunakan pakaian yang sopan.

Selain melayani secara lahir, istri juga melayani suaminya secara batin melalui pemenuhan kebutuhan biologisnya. Ajaran ini tersirat dalam bait ke-16 berikut.

Den grahita sira nini / ing karsane lakinira/ manawa ana karsane / nini enggal anaria / lamun amba cangkrama / sumaraha marang kakung / iku wadon kang utama // (Serat Patimah, bait 16)
Maka mengertilah kamu Pada keinginan suamimu Siapa tahu ada keinginannya Segera tawarilah Jika lama bercengkerama Pasrahlah kepada sang suami Itulah wanita yang utama

Kutipan itu berisi ajaran untuk memahami keinginan suami, termasuk keinginan biologis suami. Lebih dari itu, kutipan itu juga mengajarkan agar seorang istri selalu siap melayani suaminya dengan tulus dan ikhlas. Termasuk ketika istri sedang melakukan kesibukan sedangkan suami memanggilnya dan membutuhkannya, hendaknya istri meninggalkan kesibukannya dan segera melayani suaminya. Ajaran ini tersirat dalam bait ke-7 berikut.

ana lenggana laki/ nadyan sira nambut karyal yen den undang ing kakungel aglis sira sumauri/ kebat sira maraal aja sira apitambuh/ iku celaning wadon// (Serat Patimah, bait 7)
Ada tidak mau kepada suami Meskipun kamu sedang bekerja Jika dipanggil suami segeralah kamu menjawab Datanglah kamu dengan cepat Jangan kamu pura-pura tidak tahu Karena itu buruknya seorang istri 
Kutipan itu mengandung ajaran agar istri harus acuh kepada suaminya dan selalu ada ketika suami membutuhkannya. Ketika suami memanggil, istri harus cepat menjawab panggilannya. Pada kutipan itu juga disebutkan jika istri tidak memperdulikan panggilan suami, istri semacam itu adalah istri yang tidak baik.

4. Seorang Istri harus menurut kepada suaminya.

Seorang wanita, ketika belum menikah, merupakan tanggung jawab orangtuanya. Sehingga, dia harus lebih mengutamakan orang tuanya daripada orang lain. Sebaliknya, ketika seorang wanita telah menikah, tanggung jawab itu beralih kepada suaminya. Sehingga, hak suami menjadi lebih besar daripada orang tuanya. Untuk itu, kewajiban seorang istri adalah mengutamakan dan menuruti suaminya dalam segala hal. Sikap menurut kepada suami tersirat pada bait ke-4 berikut.

yen sira amangan nini / aja bareng lakenira / utawi dhingini mangke / iku nini tan prayoga / yen patrap kang mangkana/ lan malih wonten dinulu / wanodya patrap mangkana // (Serat Patimah, bait 4)
Jika kamu makan Jangan bersama suamimu Atau itu memang keinginannya Itu wanita yang baik Jika yang diminta seperti itu Dan ada pembicaraan Perempuan pantas seperti itu

Dalam kutipan itu dicontohkan ketika suami makan, hendaknya istri tidak ikut makan bersama, kecuali jika suami memang menghendaki untuk makan bersama. Pada kutipan itu tersirat ajaran untuk selalu menuruti dan mematuhi apapun keputusan suami sebagai kepala dan pemimpin dalam rumah tangga. Untuk itu, istri harus mengikuti apapun keputusan suaminya.

Selain bait keempat, bait lainnya yang berisi ajaran untuk menuruti suami adalah bait kelima.

malah utamaning estri / madhepa karsaning priya / angantia sak kadare / lan aja sira sasanjan / nadyan awrat ing karya / paminta sira karuhun / iya marang lakenira // (Serat Patimah, bait 5)
Justru keutamaan dari perempuan Menuruti kehendak suami

Sampai akhir hayat

Dan jangan kamu mengeluh

Meskipun berat ketika melakukannya

Permintaanmu dikabulkan

Oleh suamimu juga 
Bait itu berisi ajaran untuk menuruti kehendak suami sampai akhir hayatnya. Pada bait itu juga disebutkan agar istri dengan tulus, ikhlas, dan tidak mengeluh ketika menjalani perintah suami meskipun segalanya dirasakan berat oleh istri.

5. Seorang istri harus menghormati tamu.

Dalam pupuh ini juga disebutkan ajaran untuk menyambut tamu dengan baik.

yen wonten tatamu prapti/

adoh sangking sangkaniral

kebat sapanen den age kang sareh/

pangucap iral

den ajer ulat iral

anulya konen alungguh/

prenahna dhadhayoh ira //

(Serat Patimah, bait 8)
Jika ada tamu yang datang

Tanpa disangka-sangka

Segeralah menyapanya dengan halus perkataanmu

Jangan kamu memandang dengan curiga

Lebih baik disuruh duduk terlebih dahulu

Dijamu dengan baik tamu itu

Bait kedelapan itu menceritakan jika ada tamu yang datang dengan tiba-tiba tanpa ada pemberitahuan sebelumnya, hendaknya istri menerima tamu itu dengan baik. Istri harus menyapa dengan perkataan halus, menyilakan duduk, menjamunya, dan tidak memandangnya dengan curiga.

Adab menerima tamu ini juga terdapat dalam bait ke-9 berikut.

lamun darbe siba nini /

dayoh ira rejanana /

iya nini sak kadare /

yen tan darbe pra sabena /

supaya ingapura /

ing sakehing dosanipun /

iya sangking lakenira //

(Serat Patimah, bait 9)
Jika tamu datang

Muliakanlah beliau sebagai tamu

Walaupun hanya seadanya

Jika tidak punya apa-apa

Agar dimaafkan

Semua dosa itu

Iya dari suamimu

Pada bait itu disebutkan untuk memuliakan tamu dengan jamuan seadanya dan tidak berlebihan. Suami sebagai kepala rumah tangga bertanggung jawab untuk memberi nafkah kepada keluarganya. Namun, jika di dalam rumah tidak terdapat makanan ataupun minuman untuk dihidangkan kepada tamu, istri tidak boleh mengeluh dan tidak boleh menyalahkan suami. Istri hendaknya memaafkan suami agar dosanya diampuni oleh Allah.

Ajaran-ajaran yang telah disebutkan itu merupakan ajaran dari Nabi kepada Fatimah untuk berbakti pada suami ketika suami masih hidup. Lebih dari itu, dalam pupuh Asmaradana bait ke-23 juga disebutkan ajaran untuk berbakti kepada suami yang telah meninggal dunia. 
kalamun tinilar priya /

ing wuri ganti tapake /

anerusi ing tatangga /

tan mikir kakung prapta /

giwanging driya kapungkur /

sri nata kang aneng ngarsa //

(Serat Patimah, bait 23)
Seandainya ditinggal suami

Berganti langkahnya dibelakang

Meneruskan ke tetangga

Tidak memikirkan kedatangan suaminya

Berubahnya perasaan di masa lalu

Mengatur-atur di bagian depan

Pada bait itu disebutkan jika seorang istri ditinggal meninggal oleh suaminya, dia harus bisa menjadi pemimpin rumah tangga menggantikan posisi suaminya. Pada bait itu juga diajarkan agar istri mengikhlaskan kepergian suaminya dengan tidak mengingat-ingat dan mengharapkan suaminya kembali. Dia harus melupakan masa lalu dan menyongsong masa depan demi dirinya sendiri dan anak-anaknya.

Dalam Serat Patimah juga disebutkan keutamaan seorang istri berbakti kepada suami. Pertama, istri yang berbakti kepada suami dengan tulus dan ikhlas akan mendapatkan kebahagiaan di dunia. Dia dan suami akan menjadi pasangan yang diliputi dengan kebaikan. Seperti yang tersirat dalam bait berikut.

anedha asih ing laki / pangapurane wong lanang / ing donya prapteng akhire / kinasihana ing priya / antuk sih kang nugraha / linebura dosanipun / pinanjing nating sawarga // (Serat Patimah, bait 10)

\author{
Mengasihi suami \\ Maafkanlah suami \\ Di dunia sampai akhir \\ Sayangilah suami \\ Agar mendapat anugerah \\ Dihapuskan dosanya \\ Dan mendekat ke surga
}

Kedua, keutamaan seorang istri yang berbakti kepada suami dengan tulus dan ikhlas akan mendapatkan pahala dan surga. Keutamaan ini tersirat dalam bait berikut.

pawestri kang bekti nglaki / ing bejang dina kiyamat / cinadhang suwarga kaot / margane bekti ing priya / tuhu estri utama / wong lanang liwat sihipun / alah guna paran-paran // (Serat Patimah, bait 11)
Istri yang berbakti kepada suami Di akhir hari kiamat ikut ke surga Karena berbakti kepada suami Sungguh istri yang utama Laki-laki lewat asihnya Akan bermanfaat tujuannya

Istri yang berbakti dan sayang kepada suami merupakan istri yang utama. Dia akan mendapatkan pahala dari apa yang telah dia lakukan. Sehingga, ketika 
hari kiamat, istri akan ikut suami ke surga. Keutamaan istri yang berbakti masuk ke surga juga tersurat dalam bait ke-20 dan 22 berikut.

apan iku sira nini / wulangipun marang sira / pan aja patrap mangkana / pan sira nama wanodya / ginajaraken priya / mumbula langit kapitu / sira maksih kaungkulan // (Serat Patimah, bait 20)

sakathahe ing pawestri / aja na sak marang priya / mugi tiniruwa mangke / paniku wadon utama / karam manjing naraka / kang murat langkung jumurung / sasat ratu wanudya // (Serat Patimah, bait 22)
Karena itu anakku

Ajaran untuk dirimu Jangan melakukan hal seperti itu Sebab kamu wanita Harus berbakti pada suami Naiklah langit ke tujuh Kamu masih terungguli

Kebanyakan seorang istri Jangan ada yang menyela suami Semoga nanti dapat ditiru Itu wanita utama Haram baginya mendekati neraka Itu pantas baginya

Layaknya ratu para wanita

Pada bait ke-20 tersebut berisi ajaran agar istri harus berbakti kepada suami agar naik ke langit ketujuh. Yang dimaksud dengan langit ketujuh ialah surga yang penuh dengan kemuliaan dan kebahagiaan. Begitu juga dengan bait ke-22. Pada bait ke-22 juga disebutkan bahwa istri yang berbakti kepada suami merupakan wanita yang utama. Pada bait itu diumpamakan istri yang berbakti kepada suami bagaikan ratu yang memiliki keleluasaan masuk surga dan diharamkan baginya masuk neraka.

Dalam pupuh itu juga disebutkan agar Fatimah dapat menjadi tauladan bagi wanita untuk menjadi istri yang sholehah dan berbakti kepada suaminya.

angandika Kanjeng Nabi /

amulang dhateng kang putra/

Gusti Patimah putrane /

ah anak isun Patimah /

poma amituhua /

ingsun suwan ing Hyang Agung /

dadiya panutan sirall

(Serat Patimah, bait 17)
Perkataan kanjeng Nabi

Mengajarkan pada anak-anaknya

Gusti Patimah anaknya

Anakku Patimah

Hendaklah menurut

Aku memohon pada Tuhan

Semoga kamu menjadi panutan

Bait ke-17 itu merupakan perkataan Nabi kepada Fatimah agar kesucian, kemuliaan, dan kesholehah Fatimah dapat menjadi tauladan bagi para istri.

\section{Kesimpulan}


Sesuai dengan judulnya, Serat Patimah merupakan teks yang terpengaruh ajaran Islam. hal itu dapat dilihat dari isinya yang menggambarkan nasihat Nabi Muhammad kepada putrinya. Seperti diketahui, Nabi Muhammad merupakan panutan umat Islam. Oleh karena itu, diharapkan dengan membaca teks ini para wanita Islam mau mematuhinya. Ajaran-ajaran yang terdapat dalam Serat Patimah hendaknya dapat menjadi tauladan bagi para istri. Dengan demikian, diharapkan agar kehidupan rumah tangganya dapat berjalan dengan baik dan agar istri mendapat barokah di dunia serta akhirat.

\section{Daftar Pustaka}

Baroroh Baried, Siti, dkk. 1994. Pengantar Teori Filologi. Yogyakarta: Badan Penelitian dan Publikasi Fakultas Sastra Universitas Gadjah Mada.

Marsono. 2008. "Centhini: Karya Masterpiece Pujangga Jawa" dalam "Kumpulan Makalah Seminar Mengungkap Kolaborasi Isi dan Peluncuran Saduran Serat Centhini Jilid V-XII”. Yogyakarta: Jurusan Sastra Nusantara Fakultas Ilmu Budaya Universitas Gadjah Mada.

Poerbatjaraka, R.M.Ng. dan Tardjan Hadidjaja. 1952. Kepustakaan Djawa. Jakarta: Djambatan.

Robson, S. O. 1978. "Pengkajian Sastra-sastra Tradisional Indonesia" dalam Bahasa dan Sastra Tahun IV Nomor 6. Jakarta: Pusat Pembinaan dan Pengembangan Bahasa Departemen Pendidikan dan Kebudayaan.

Zoetmulder, P.J. 1994. Kalangwan: Sastra Jawa Kuno Selayang Pandang. Jakarta: Djambatan. 